\title{
Thymus Sahraouian Essential Oil as Corrosion Eco-friendly Inhibitor for Mild Steel in a Molar Hydrochloric Acid Solution
}

\author{
Z. Bensouda ${ }^{a, *}$, M. Driouch ${ }^{a}$, R.A. Belakhmima ${ }^{b}$, \\ M. Sfaira ${ }^{a}$, M. Ebn Touhami ${ }^{b}$ and A. Farah ${ }^{c}$ \\ ${ }^{a}$ Laboratoire d'Ingénierie des Matériaux, de Modélisation et d'Environnement (LIMME). \\ Université Sidi Mohamed Ben Abdellah (USMBA), \\ Faculté des Sciences, BP 1796-30000, Fez-Atlas, Morocco \\ ${ }^{b}$ Laboratoire d'Ingénierie des Matériaux et Environnement: Modélisation et Application, \\ Faculté des Sciences, Université Ibn Tofaïl, BP. 133-14000, Kénitra, Morocco \\ ${ }^{c}$ Laboratoire de Chimie Organique Appliquée. Université Sidi Mohamed Ben Abdellah \\ (USMBA), Faculté des Sciences et Techniques. Route Immouzer, Fez, Morocco
}

Received July 25, 2017; accepted December 12, 2017

\begin{abstract}
Thymus Sahraouian essential oil (TSEO), as a new corrosion eco-friendly inhibitor, has been used to protect mild steel in $1 \mathrm{M} \mathrm{HCl}$. Weight loss, three potentiodynamic polarization methods (Tafel, Stern and Stern-Geary), and electrochemical impedance spectroscopy measurements were undertaken to evaluate corrosion inhibition by TSEO. TSEO acted as an efficient corrosion inhibitor for mild steel in $1 \mathrm{M} \mathrm{HCl}$, and its inhibition efficiency increased with a concentration of $77.82 \%$ at $2 \mathrm{~g} \mathrm{~L}^{-1}$. The polarization curves revealed that TSEO acted as a mixed type inhibitor, with predominant anodic action. The EIS studies were fitted to a suitable equivalent circuit model, at $293 \mathrm{~K}$, only reflecting a one-time constant characteristic of a charge transfer process. Besides, the higher is the temperature the lowest is the inhibiting efficiency. The kinetic parameters were in favour of an electrostatic character of TSEO components adsorption onto the mild steel surface, and adsorption followed the Langmuir isotherm model. Micrographic scanning electron microscopy and energy dispersive X-ray spectroscopy analyses confirmed the formation of a protective adsorbed film upon the mild steel surface.
\end{abstract}

Keywords: acid corrosion; mild steel; green inhibitor; polarization curves; EIS; SEM/EDX.

\footnotetext{
* Corresponding author. E-mail address: bensouda@yahoo.com
} 


\section{Introduction}

Corrosion is a set of electrochemical and/or chemical reactions between a material, usually a metal, and the environment, which produces a deterioration of its characteristics. The three main reasons for the importance of corrosion investigations are economy, conservation, and safety [1]. In diverse forms of corrosion, there is practically no visible weight change or degradation, but properties change, and the metal may fail without warning, because of certain changes within it. Such changes may defy normal visual examination or weight change determinations [2].

Nowadays, acid solutions are commonly used in industry, the most important fields of application being industrial acid cleaning, acid pickling, acid descaling, oil-well acid in oil recovery, and the petrochemical process. Because of the specific corrosiveness of acid solutions, corrosion inhibitors are commonly used to reduce the corrosive attack on metallic materials [3].

A corrosion inhibitor is a chemical element or combination of elements that, when added, at small concentrations, to an aggressive environment, effectively reduce the corrosion rate of the metal exposed to it. Mineral compounds such as chromates, phosphates and molybdates act as anodic inhibitors [4].

Organic compounds containing heteroatoms such as oxygen, phosphor, nitrogen, sulfur and multiple bonds in their molecules form a protective film through the adsorption of their potential sites onto the metal surface [5 and 6]. The use of organic and mineral corrosion inhibitors has been restricted, due to their toxicity to both human beings and the environment. In fact, their synthesis is often expensive and insufficiently efficient at low dosages [7], which limits their application.

Currently, research in corrosion is focused on "eco-friendly corrosion inhibitors" that show a low risk of environmental pollution, with good inhibition efficiency [8]. The term "eco-friendly inhibitor" or "green inhibitor" refers to substances that are biocompatible, such as essential oils, since they are of biological origin [9]. Eco-friendly inhibitors can be used in the form of pure compounds [10-11], essential oils [5, 12-13], or plant extracts [14-16].

Plant extracts can be used in chemical cleaning and pickling processes, and all of them have been found to generally exhibit good inhibition efficiencies. The yield of eco-friendly inhibitors and their corrosion inhibition capacity widely vary, depending on the used plant parts, harvest time, climatic conditions and geographic location [17].

In the last decade, wide research has been made on some essential oils of Thymus derivatives as potential corrosion inhibitors for different metals in various acid solutions [18-24]. For instance, the protection of mild steel, tinplate and copper in $\mathrm{HCl}, \mathrm{H}_{2} \mathrm{SO}_{4}$ and $\mathrm{HNO}_{3}$ solutions by Thymus derivatives essential oils, based on gravimetric and electrochemical techniques, has been reported by some researchers [18, 20, 22, 24].

Results indicate that the inhibition efficiency increased with the higher essential oil concentrations, and decreased with the rise in temperature. Similarly, Elbouchtaoui et al. [21] have investigated the effect of Thymus pallidus essential 
oil on carbon steel in $\mathrm{HCl}$. The obtained results revealed that the essential oil reduced the corrosion rate.

El Hajjaji et al. [19] showed that Thyme vulgaris essential oil is a good corrosion inhibitor for mild steel in $1 \mathrm{M} \mathrm{HCl}$. According to all results, Thyme derivatives essential oils acted as mixed type inhibitors on the metal surface.

The aim of the present work is to study the effect of Thymus Sahraouian essential oil, (hereafter denoted TSEO), as a corrosion inhibitor for mild steel in molar hydrochloric acid. Thymus $S$. plant is cultivated in the southeast of Morocco, for application in the pharmaceutical industry, and for medicinal purposes.

TSEO was obtained by hydro distillation technique using a Clevenger type apparatus, and analysed by gas chromatography and gas chromatography-mass spectrometry techniques. Examination of mild steel corrosion parameters in a molar hydrochloric solution was achieved by means of gravimetric, potentiodynamic polarization and electrochemical impedance spectroscopy (EIS) methods.

The mild steel surface morphology was recorded by Scanning Electron Microscope (SEM), associated to Energy Dispersive X-ray spectroscopy (EDX). The mechanism of mild steel corrosion inhibition is herein deeply discussed, based both on the confrontation of the adsorption isotherm with temperature dependence.

\section{Experimental procedure \\ Plant material and its extraction}

Specimens of Thymus $S$. plant came from the city of Tighremt N'Imgounen (located in the southern of Morocco in the Draa-Tafilalet region). They were collected in the late spring, during the plant flowering period, and only the aerial parts (flowers, leaves, stems) were gathered. TSEO was obtained by hydro distillation realized by boiling the aerial part of Thymus $S$. plant for $3 \mathrm{~h}$. The mean yield of this inhibitor was $1.49 \mathrm{~mL} / 100 \mathrm{~g}$ of dry substance.

TSEO was dehydrated over $\mathrm{Na}_{2} \mathrm{SO}_{4}$. The obtained essential oil was analysed by Gas Chromatography - Mass Spectrometry (type QP2010 Shimadzou ${ }^{\circledR}$ ) and by Trace gas chromatography / Polaris Q (Gas Chromatography - Mass Spectrometry, Thermo-Electron ${ }^{\circledR}$ ). The column of gas chromatography used helium as mobile phase, and it had $95 \%$ dimethyl-polysiloxan and $5 \%$ phenyl, with a length of $30 \mathrm{~m}$, a layer thickness of $0.25 \mu \mathrm{m}$, and an interior diameter of $0.24 \mu \mathrm{m}$.

\section{Coupons preparation}

The chemical composition of mild steel specimens (wt. \%) used for all the experiments was as follows: $\mathrm{P}=0.013, \mathrm{Mn}=0.4, \mathrm{Si}=0.1, \mathrm{~S}=0.02, \mathrm{C}=0.16$ and Fe balance. The used mild steel specimens had a rectangular form (length $=3 \mathrm{~cm}$, width $=1 \mathrm{~cm}$, thickness $=0.05 \mathrm{~cm}$ ). This size was used for weight-loss measurements and SEM analyses, whereas specimens with the size of length = $6 \mathrm{~cm}$, width $=1 \mathrm{~cm}$ and thickness $=0.05 \mathrm{~cm}$, with only $1 \mathrm{~cm}^{2}$ of exposed 
surface, were used as working electrodes for potentiodynamic polarization and EIS measurements.

The metal specimens were pre-treated previously to the experiments by mechanically polishing with SCI emery-papers, successively from 180 to 2000 grades. The samples were completely washed with bi-distilled water, defatted by absolute ethanol, and dehydrated with acetone at room temperature, before being immersed into the corrosive media, so that they were all in similar conditions.

\section{Test solutions}

The aggressive solution $(1 \mathrm{M} \mathrm{HCl})$ was prepared by dilution of analytical reagent grade, $37 \% \mathrm{HCl}$, with bi-distilled water. All the test solutions were freshly prepared before every experiment, by directly adding TSEO into the aggressive solution. The concentration of the essential oil used ranged from 0.5 to $2 \mathrm{~g} \mathrm{~L}^{-1}$, and the solution volume was $50 \mathrm{~mL}$ in every experiment.

\section{Gravimetric and electrochemical measurements}

The gravimetric measurements were realized in a double glass cell equipped with a thermostat cooling condenser. Hence, the gravimetric results expressed in $\left(\mathrm{mg} \mathrm{cm}^{-2} \mathrm{~h}^{-1}\right)$ were given after $6 \mathrm{~h}$ immersion time at room temperature $(293$ $\pm 1 \mathrm{~K})$, by weighting the cleaned specimens before and after immersion in the corrosive solution, using a digital balance with $0.001 \mathrm{~g}$ of sensitivity. The exposed area of used samples was $6.4 \mathrm{~cm}^{2}$. Three experiments were performed in each case, and the mean value was reported.

The electrochemical workstation was VoltaLab Radiometer ${ }^{\circledR}$ PGZ100 potentiostat controlled by a Portable Computer, and supported by Voltamaster 4 software. The electrochemical measurements were performed using a conventional three-electrode cell with a thermostatted double wall. The mild steel specimen was used as working electrode; a saturated calomel electrode as reference electrode; and a platinum electrode as auxiliary electrode. The working electrode was the one used for weight-loss measurements, embedded in polytetrafluoroethylene (PTFE), to avoid any electrolyte infiltration.

The polarization curves acquired from potentiodynamic polarization experiments were recorded in the potential range from -900 to $-100 \mathrm{mV}$ (SCE), with $1 \mathrm{mV} \mathrm{s}^{-1}$ scan rate. The potentiodynamic Tafel measurements were scanned starting from cathodic to the anodic domain, from $-200 \mathrm{mV}_{\mathrm{SCE}}$ to +200 $\mathrm{mV}$ SCE. The linear Tafel segments of the cathodic curves allowed providing the cathodic Tafel slopes $(\beta c)$, and their extrapolation to $E_{\text {corr }}$ gave the corrosion current density ( $i_{\text {corr }}$ ).

The polarization resistance $\left(\mathrm{R}_{\mathrm{p}}\right)$ of mild steel in the test solutions was calculated by performing linear polarization experiments in the potential range of \pm 10 $\mathrm{mV}_{\mathrm{SCE}}$, apart from $\mathrm{E}_{\mathrm{corr}}$, with a scan rate of $1 \mathrm{mV} / \mathrm{s}$. The slope of the obtained current versus potential curves yielded the polarization resistance value.

The impedance experiments were realized using a transfer function analyser (Voltalab PGZ 100), in the frequency range domain from $100 \mathrm{kHz}$ to $100 \mathrm{mHz}$, with a small perturbation amplitude of $10 \mathrm{mV}$ peak to peak, at the open circuit 
potential. The working electrode was immersed for $30 \mathrm{~min}$ in the acidic solution, before starting the EIS measurements.

The steady-state current voltage characteristics were performed by using EcLab software, where all EIS data were fitted and analysed with the Ec-Lab simulation, as well as $\mathrm{ZView}^{\circledR} 2.80$, with respect to an appropriate equivalent circuit.

\section{Morphological investigation}

In order to examine the changes in surface morphology of the corroded and inhibited samples, SEM model FEI Quanta ${ }^{\circledR}$ 200, equipped with EDAX probe microanalysis of surfaces, was used. The micrographs were taken after immersion of the samples for $24 \mathrm{~h}$ in the corrosive solution, without and with $2 \mathrm{~g}$ $\mathrm{L}^{-1}$ of TSEO.

\section{Results and discussion}

\section{Characterization and chemical composition of TSEO}

Fig. 1 shows the spectre of gas chromatography and gas chromatography-mass spectroscopy of the essential oil dissolved in hexane.

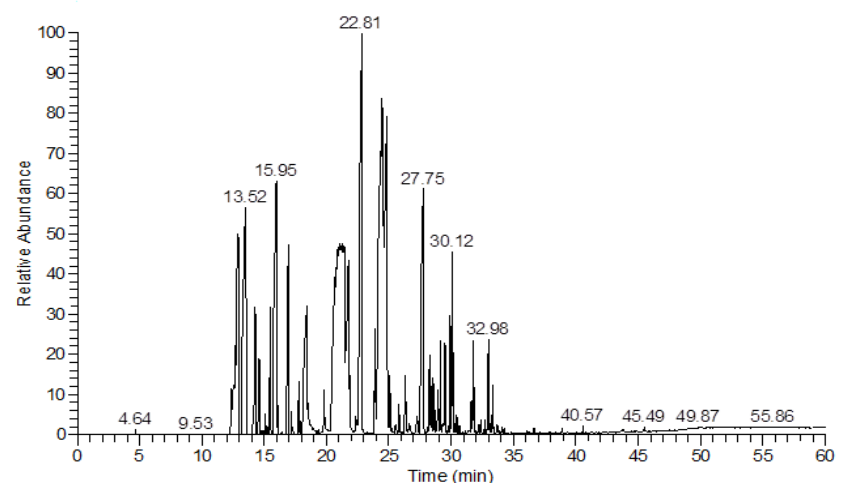

Figure 1. Spectrum of gas chromatography and gas chromatography - mass spectrometry of TSEO

Table 1 summarizes the obtained component percentages of TSEO. The total detected for this essential oil was of $99.98 \%$.

Table 1. Chemical composition of TSEO.

\begin{tabular}{|c|c|c|c|}
\hline Constituent & $\%$ & Constituent & $\%$ \\
\hline Durenol & 37.6 & 3-Carene & 1.9 \\
\hline $\begin{array}{l}{[(\{2-[4-(\text { Benzylsulfonyl)-3- }} \\
\text { methylcyclohexyl]propyl }\} \text { sulfonyl)methyl]benzene }\end{array}$ & 9.72 & Epizonarene & $3^{1.6}$ \\
\hline 3-Carene & 9.3 & $1,2,3,4$ Tetramethylfulvene & 1.5 \\
\hline Isodurene & 8.99 & Bicyclosesquiphellandrene & 1.4 \\
\hline Cyclohexanone, 2-(2-nitro-2-propenyl) & 7.52 & Isoaromadendrene epoxide & 1.3 \\
\hline Phosphoric acid, tribornyl ester & 6.3 & $\alpha$-Cubebene & 0.9 \\
\hline Dysokusone D & 4.03 & $\alpha$-Farnesene & 0.9 \\
\hline$\alpha$-Muurolene & 3.83 & Terpinolene & 0.4 \\
\hline p-tertio-Butylcatechol & 2.24 & & \\
\hline
\end{tabular}


The chemical structures of the major abundant compounds are presented in Fig. 2.<smiles>Cc1cc(C)c(C)c(O)c1C</smiles>

Durenol: $\mathrm{C}_{10} \mathrm{H}_{14} \mathrm{O} \mathbf{3 7 . 6 4 \%}$<smiles>Cc1cc(C)c(C)c(C)c1</smiles>

Isodurene: $\mathrm{C}_{10} \mathrm{H}_{14} \mathbf{8 . 9 9 \%}$

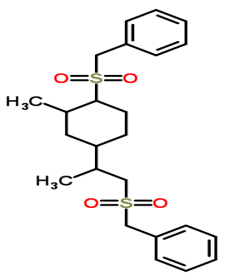

[(\{2-[4-(Benzylsulfonyl)-3methylcyclohexyl]propyl\}sulfonyl) methyl]benzene: $\mathrm{C}_{24} \mathrm{H}_{32} \mathrm{O}_{4} \mathrm{~S}_{2}$ $9.72 \%$<smiles>C=C(CC1CCCCC1=O)[N+](=O)O</smiles>

Cyclohexanone,2-(2-nitro-2propenyl): $\mathrm{C}_{9} \mathrm{H}_{13} \mathrm{NO}_{3} 7.52 \%$<smiles>CC1=CCC2C(C1)C2(C)C</smiles>

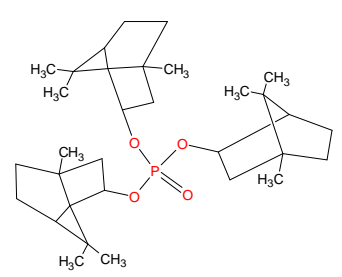

Phosphoric acid, tribornyl ester : $\mathrm{C}_{30} \mathrm{H}_{51} \mathrm{O}_{4} \mathrm{P} 6.3 \%$

Figure 2. Chemical structures of the major molecules in TSEO.

\section{Gravimetric study}

The effect of TSEO, at different concentrations, on the corrosion inhibition of mild steel in $1 \mathrm{M} \mathrm{HCl}$ solution, was calculated by using the gravimetric method at $293 \mathrm{~K}$, after an immersion period of $6 \mathrm{~h}$. The corrosion rate $\left(\mathrm{W}_{\text {corr }}\right)$ and the inhibition efficiency ( $\left.\eta_{w L} \%\right)$ are calculated by Equation (1) [25]:

$$
\eta_{W L} \%=\left(1-\frac{W_{i n h}}{W_{0}}\right) \times 100
$$

where $W_{\text {inh }}$ and $W_{0}$ are the values of corrosion weight-loss in inhibited and uninhibited solutions, respectively.

The evolution of both $\mathrm{W}_{\text {corr }}$ and $\eta_{\mathrm{WL}} \%$ versus TSEO concentration is shown in Fig. 3.

It can be concluded that the corrosion rate decreased, while the inhibiting efficiency increased with the rise of TSEO concentration in the aggressive solution. The maximum $\eta_{\mathrm{wL}} \%$ of $78.31 \%$ was achieved at $2 \mathrm{~g} \mathrm{~L}^{-1}$ of TSEO, and any additional increase in TSEO concentration did not modify the inhibitor performance. These results imply that this essential oil is a good corrosion inhibitor for mild steel in a $1 \mathrm{M} \mathrm{HCl}$ solution, and that the corrosion inhibition can be imputed to the adsorption of some TSEO components onto the mild steel/hydrochloric acid solution interface [16]. 
Indeed, the adsorption of TSEO components, involving the displacement of water molecules from the mild steel surface, can occur because of the eventual formation of links between the vacant d-orbital of iron atoms, and the free lone pair electrons present on $\mathrm{O}, \mathrm{S}, \mathrm{N}$ and $\mathrm{P}$ atoms, along with the $\pi$-orbital's of the major TSEO components (cf. Fig. 2). Similar results were reported by Rani and Basu [26], and Hussin et al. [27]. Nevertheless, the inhibiting character of this essential oil can also be ascribed to a synergistic, or otherwise, effect of its various active components, despite minor compounds (Table 1). Boumhara et al. [5] revealed that the inhibitive nature of Artemisia Mesatlantica may be attributed to the synergistic intermolecular effect of the different active constituents present in the essential oil.

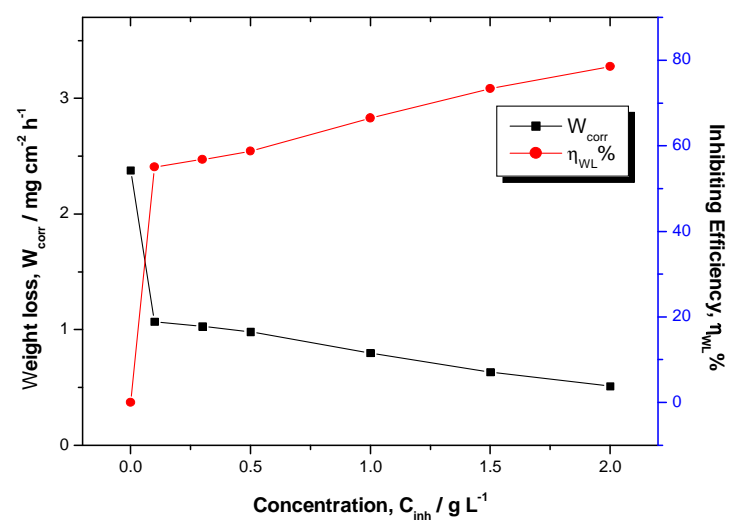

Figure 3. Corrosion rate and inhibiting efficiency of mild steel exposed for $6 \mathrm{~h}$ in $1 \mathrm{M}$ $\mathrm{HCl}$, at different concentrations of TSEO at $293 \mathrm{~K}$

\section{Electrochemical measurements}

Potentiodynamic polarization study

Potentiodynamic polarization measurements have been carried out, in order to gain information about the kinetics of the cathodic and anodic reactions. Potentiodynamic polarization curves of mild steel in $1 \mathrm{M} \mathrm{HCl}$, without and with different concentrations of TSEO at $293 \mathrm{~K}$, are given in Fig. 4.

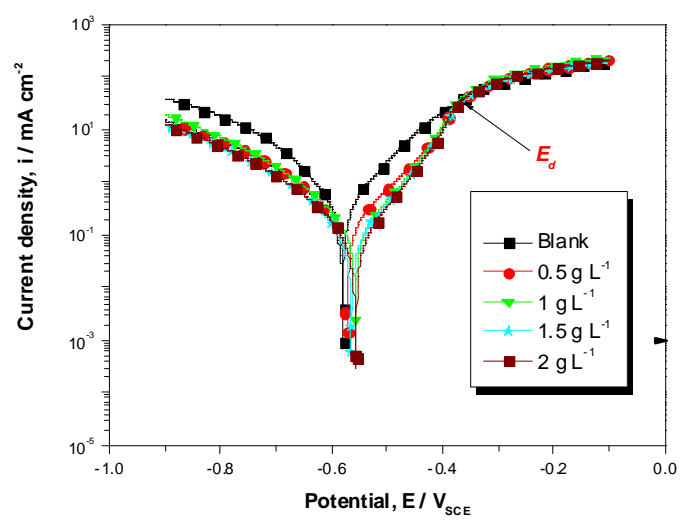

Figure 4. Polarization curves of mild steel in $1 \mathrm{M} \mathrm{HCl}$, at different concentrations of TSEO at $293 \mathrm{~K}$. 
This figure shows that both cathodic and anodic current densities in the presence of the TSEO inhibitor have been significantly decreased with respect to those of the $1 \mathrm{M} \mathrm{HCl}$ solution. In addition, the shift in the corrosion potential achieved more positive potentials when TSEO was added, which corresponds to a manifest anodic inhibition. The cathodic current-potential of mild steel, in the absence and presence of different TSEO concentrations, gave rise to parallel Tafel lines, which means that the hydrogen evolution reaction was activation controlled. Thus, the reduction of $\mathrm{H}^{+}$, at the mild steel interface, essentially took place through a charge transfer mechanism [28-29]. Furthermore, in the anodic region, TSEO inhibition mode depended on the applied potential. Indeed, TSEO acted as a corrosion inhibitor only at low anodic over-potentials below $\mathrm{E}_{\mathrm{d}} \approx 0.362 \mathrm{~V}_{\mathrm{SCE}}$, whereas current densities sharply increased in the presence of TSEO at higher potentials than $E_{d}$ [30-31]. Thus, the mechanism of the metallic dissolution reaction was changed. This behavior may be the result of a significant dissolution of iron, leading to the removal and/or deformation of the TSEO film at the mild steel surface; this potential is generally defined as the desorption potential. It is then concluded that TSEO molecules adsorption onto the mild steel surface creates a film that protects it at low anodic over-potentials. This film loses its protection when the potential is augmented to higher anodic regions. Similar results have been reported in the literature [30-33].

The corrosion inhibiting efficiency values obtained from the Tafel method are calculated, as according to Equation (2):

$$
\eta_{\text {Tafel }} \%=\left(1-\frac{i_{\text {corr } / \text { inh }}}{i_{\text {corr }}}\right) \times 100
$$

where $i_{\text {corr }} /$ inh and $i_{\text {corr }}$ represent the corrosion current density values, with and without TSEO, respectively.

Table 2. Electrochemical data evaluated from the cathodic current-voltage characteristics for the mild steel/1 M HCl system, without and with TSEO at $293 \mathrm{~K}$.

\begin{tabular}{|c|c|c|c|c|c|c|}
\hline Concentration & & Tafe & ata & & Stern & ary data \\
\hline $\begin{array}{l}\mathrm{C}_{\text {inh }} \\
\mathrm{g} \mathrm{L}^{-1}\end{array}$ & $\begin{array}{l}\text { Ecorr }_{\text {mV/SCE }} \\
\mathrm{mV}\end{array}$ & $\begin{array}{l}I_{\text {corr }} \\
\mu \mathrm{A} \mathrm{cm}^{-2}\end{array}$ & $\begin{array}{l}-\beta c \\
m V \operatorname{dec}^{-1}\end{array}$ & $\prod_{\%}$ & $\begin{array}{l}R_{\mathrm{p}} \\
\Omega \mathrm{cm}^{2}\end{array}$ & $\prod_{\%}$ \\
\hline Blank & -581.2 & 307.5 & 93.7 & - & 60.38 & - \\
\hline 0.5 & -576.7 & 153.4 & 100.8 & 50.11 & 143.59 & 57.94 \\
\hline 1 & -555.6 & 138.15 & 119.9 & 55.07 & 184.08 & 67.19 \\
\hline 1.5 & -563.1 & 94.77 & 109.6 & 69.15 & 241.47 & 74.99 \\
\hline 2 & -556.2 & 68.20 & 97.5 & 77.82 & 262.18 & 76.97 \\
\hline
\end{tabular}

From Table 2, it is clear that TSEO addition noticeably decreased $i_{\text {corr }}$, and that $\eta_{\text {Tafel }} \%$ considerably increased from 50.11 to $77.82 \%$. This suggests that the corrosion rate was reduced, due to the formation of a barrier film onto the mild steel surface, by adsorption of TSEO molecules. In the presence of TSEO, $\mathrm{E}_{\text {corr }}$ is anodically shifted in the range of $5-23 \mathrm{mV}$, compared to the blank solution, but all values were lower than $85 \mathrm{mV}$. This displacement greatness is not clear enough to determine the type of inhibitor: cathodic or anodic, as given elsewhere 
$[16,34]$. Hence, the obtained results imply that TSEO acted as a mixed-type inhibitor with anodic predominance, as reported by other researchers [35].

In addition, $\beta_{c}$ values show a slight change with increasing TSEO concentrations, indicating that the mechanism of hydrogen evolution discharge was not affected by the inhibitor; thereby, the reaction mechanism remained unchanged, as explained by Solmaz et al. [36]. The adsorbed protective film of TSEO onto the mild steel surface blocked the reaction sites of the mild steel. In this way, the actual surface area, accessible for $\mathrm{H}^{+}$ions, was decreased.

The polarization resistance values $\left(R_{p}\right)$ and the related percentage corrosion inhibition efficiency value $\left(\eta_{\mathrm{S} \& \mathrm{G}} \%\right)$ of mild steel in $1 \mathrm{M} \mathrm{HCl}$, in the absence and presence of various TSEO concentrations (which are determined from the Linear Polarization Resistance - LPR - method, also named Stern-Geary (S-G) [37]), are listed in Table 2. However, $R_{p}$ is determined from the current-potential curves slope in the vicinity of $\mathrm{E}_{\text {corr }} \pm 10 \mathrm{mV}$, according to Equation (3):

$$
R_{p}=\left|\frac{d E}{d i}\right|_{i \rightarrow 0}
$$

where $d i$ is the difference in the current density and $d E$ is the difference in the applied potential. The inhibition efficiency $\left(\eta_{\mathrm{S} \& \mathrm{G}} \%\right)$ is calculated from $\mathrm{R}_{\mathrm{p}}$, using the following equation:

$$
\eta_{S \& G} \%=\left(1-\frac{R_{p}}{R_{p / \text { inh }}}\right) \times 100
$$

where $R_{p}$ and $R_{p / i n h}$ are the polarization resistance values without and with TSEO, respectively.

It can be seen from Table 2 that $\eta_{S \& G} \%$ increased with a higher TSEO concentration, and achieved a maximum value of $76.97 \%$ at $2 \mathrm{gL}^{-1}$.

The Stern method, derived from potentiodynamic polarization curves, has also been used as a third method to investigate in detail the corrosion kinetic parameters [38]. To do that, the data fitting for the experimental results was made according to Equation (5):

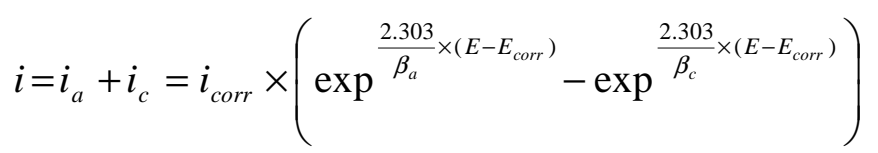

where $\beta_{c}$ is the Tafel slope of cathodic reaction and $\beta_{a}$ is the Tafel slope of anodic reaction.

Hence, for this approach, the potentiodynamic polarization studies were carried out over a potential window from -100 to $+100 \mathrm{mV}_{\mathrm{SCE}}$, with respect to $\mathrm{E}_{\mathrm{corr}}$ [39]. The potentiodynamic polarization plots (experimental and fitting) using the Stern method are illustrated in Fig. 5. A very good concordance between the experimental and fitting polarization values is observed. 


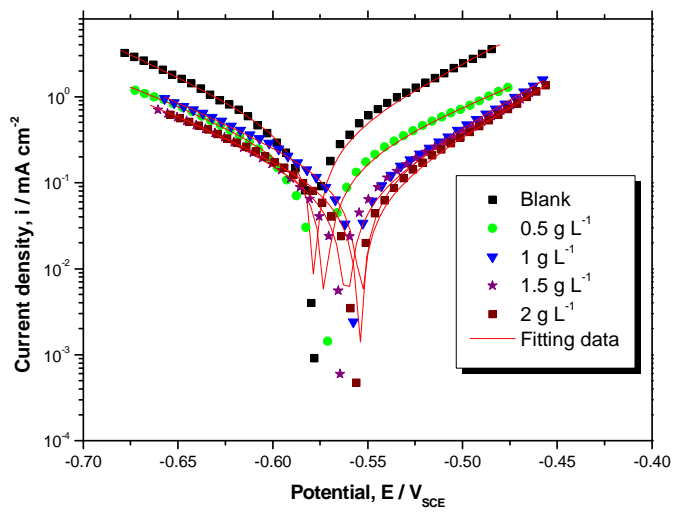

Figure 5. Comparison of experimental (scatter) and fitting (line) data using a nonlinear fitting by Stern equation for a mild steel electrode with various TSEO concentrations at $293 \mathrm{~K}$.

The Stern parameters, $i_{\text {corr }}, E_{\text {corr }}, \beta_{c}$ and $\beta_{\mathrm{a}}$, were calculated from the experimental data using the graphical data analyses software (Origin pro and Origin-Lab). The fitting quality, according to Equation (5), is judged by two parameters: the coefficient of determination $\left(\mathrm{R}^{2}\right)$ and chi-square value $\left(\chi^{2}\right)$, in which $\mathrm{R}^{2}$ reflects how close the experimental data are, when compared to the fitted regression curve, and $\chi^{2}$, given by Equation (6), represents a measurement of expectations compared to the experimental data, according to the Stern equation:

$$
\chi^{2}=\frac{1}{N} \sqrt{\sum_{i=1}^{N}\left(A_{m e s, i}-A_{c a l, i}\right)^{2}}
$$

where $A_{\text {mes, } i}$ are the measured experimental data, $A_{c a l, i}$ designates the calculated model data and $N$ corresponds to the freedom degrees.

Table 3. Stern data obtained from the polarization curves of mild steel in a $1 \mathrm{M} \mathrm{HCl}$ solution at different TSEO concentrations.

\begin{tabular}{|c|c|c|c|c|c|c|c|}
\hline $\begin{array}{l}C_{\text {inh }} \\
\mathrm{g} \mathrm{L}^{-1}\end{array}$ & $\begin{array}{l}\mathbf{E}_{\text {corr }} \\
\mathrm{mV} / \text { sCE }\end{array}$ & $\begin{array}{l}\mathbf{i}_{\text {corr }} \\
\mu \mathrm{A} \mathrm{cm}^{-2}\end{array}$ & $\begin{array}{l}-\beta_{c} \\
m V \operatorname{dec}^{-1}\end{array}$ & $\begin{array}{l}\beta_{\mathrm{a}} \\
\mathrm{mV} \operatorname{dec}^{-1}\end{array}$ & $\mathbf{R}^{2}$ & $\chi^{2}$ & $\begin{array}{l}\eta_{\text {stern }} \\
\%\end{array}$ \\
\hline Blank & $-577.9 \pm 0.6$ & $304.77 \pm 11.67$ & $96.53 \pm 5.80$ & $86.6 \pm 5.56$ & 0.968 & 0.0374 & - \\
\hline 0.5 & $-572.4 \pm 0.5$ & $164.19 \pm 5.94$ & $113.6 \pm 4.99$ & $107.6 \pm 5.20$ & 0.973 & 0.0040 & 46.12 \\
\hline 1 & $-553.3 \pm 0.6$ & $96.88 \pm 3.33$ & $102.7 \pm 5.33$ & $79.5 \pm 4.85$ & 0.976 & 0.0032 & 68.21 \\
\hline 1.5 & $-561.1 \pm 0.6$ & $73.43 \pm 2.58$ & $99.7 \pm 5.32$ & $82.7 \pm 5.14$ & 0.974 & 0.0018 & 75.90 \\
\hline 2 & $-554.2 \pm 0.5$ & $67.23 \pm 2.03$ & $101.9 \pm 5.13$ & $75.3 \pm 3.85$ & 0.985 & 0.0013 & 77.94 \\
\hline
\end{tabular}

The percentage inhibiting efficiency derived from the Stern method $\left(\eta_{\text {stern }} \%\right)$ is calculated by using corrosion current densities, according to Equation (7), identical to Equation 3:

$$
\eta_{\text {Stern }} \%=\left(1-\frac{i_{\text {corr } / \text { inh }}}{i_{\text {corr }}}\right) \times 100
$$

Referring to Fig. 5 and Table 3, it is revealed that the TSEO inhibitor addition reduced both cathodic hydrogen evolution and anodic metal dissolution 
reactions. The obtained inhibiting efficiency reached a maximum of $77.94 \%$ at 2 $\mathrm{g} \mathrm{L}^{-1}$ of TSEO. It is obvious that $\eta_{\text {stern }} \%$ followed the same trend as those of $\eta_{\text {Tafel }} \%$ and $\eta_{S \& G} \%$. The deviation was registered in the potential region from which the electrochemical parameters were extrapolated. Furthermore, the obtained chi square-values from 0.0374 to 0.0013 , and supported by the $\mathrm{R}^{2}$ values greater than 0.968 , indicate that the experimental data were well described by the Stern method. In addition, the different electrochemical parameters extracted from the Stern method are in good accordance with those obtained from Tafel, and Stern-Geary methods.
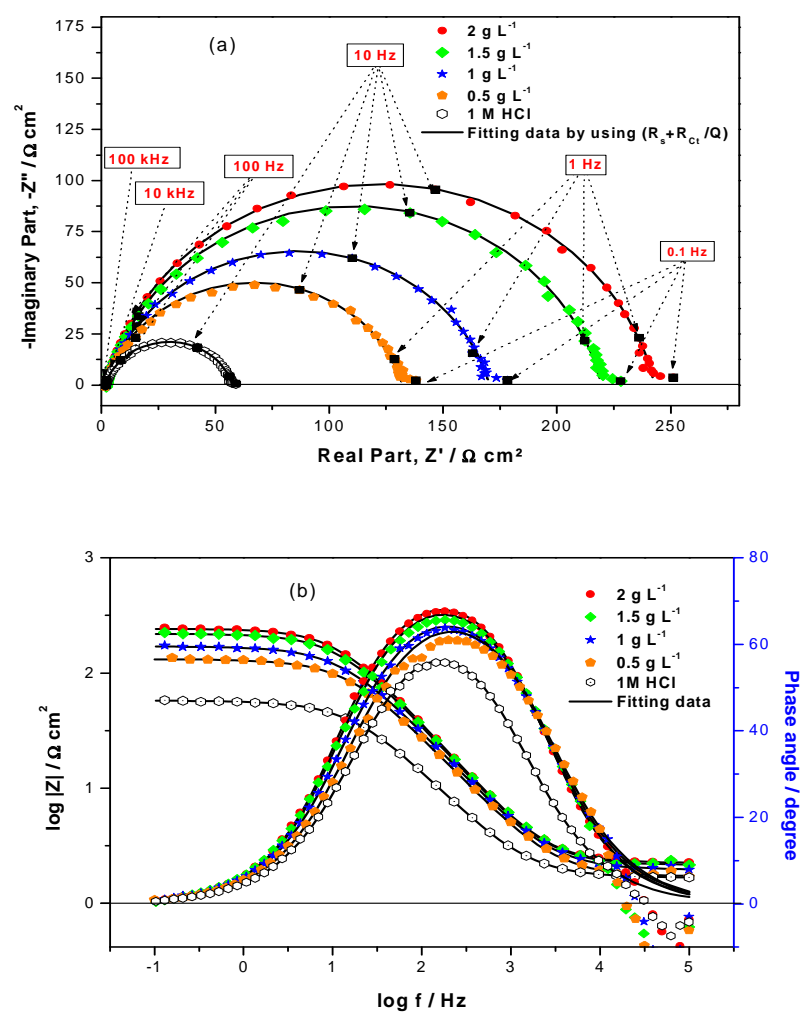

Figure 6. (a) Nyquist (Z', -Z') and (b) Bode (log f, $\log |Z|)$ and (log f, phase) diagrams of mild steel in $1 \mathrm{M} \mathrm{HCl}$ at different TSEO concentrations at $293 \mathrm{~K}$.

\section{EIS measurements}

To confirm the potentiodynamic polarization results, and to investigate the corrosion process, in terms of resistive as well as capacitive behaviour at the mild steel/solution interface, EIS technique was used. Figs. 6a-b show the impedance diagrams of mild steel in the Nyquist and Bode representations at the open circuit potential, after an exposure period of $30 \mathrm{~min}$, for $1 \mathrm{M} \mathrm{HCl}$, in the absence and presence of different TSEO concentrations

The Nyquist diagrams consist of a depressed semicircle with a single capacitive loop, of which centre is under the real axis. The deviation from a perfect semicircle is usually referred to the frequency dispersion, as well as to the inhomogeneity impurities, grain boundaries and mass transport resistance of the mild steel [40-42]. Furthermore, only one-time constant appears in $\log (\mathrm{f})-\log |\mathrm{Z}|$ plot (Fig. 6b), showing that the corrosion process was generally charge transfer 
controlled. The diameter of Nyquist diagrams increased after adding TSEO into a $1 \mathrm{M} \mathrm{HCl}$ solution, which clearly shows an enhancement in the corrosion resistance of mild steel, and indicates the adsorption of the inhibitor molecules onto the mild steel surface. The difference in real impedance at higher and lower frequencies is commonly considered as the charge transfer resistance $\left(R_{t}\right)$, while the electrolyte resistance $\left(R_{s}\right)$ is obtained from the abscissa axis intercept of the semicircle at high frequencies.

All the impedance spectra were analysed in terms of the simple modified Randles circuit (Fig. 7), which is a parallel combination of $R_{t}$ and the constant phase element of the double layer (CPE), both in series with $\mathrm{R}_{\mathrm{s}}[43]$.

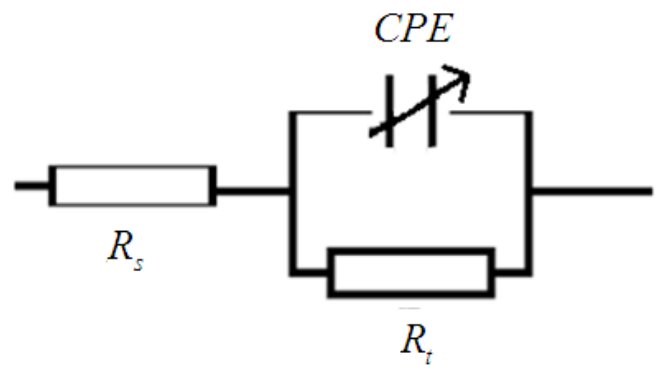

Figure 7. Equivalent circuit for the fitted impedance spectra.

A CPE was used, instead of a pure capacitor, to compensate for the non-ideal interface capacitive response, and to get a more accurate fit of the experimental data set [44]. CPE was calculated as follows:

$$
Z_{C P E}=Q^{-1}(j \times \omega)^{-n}
$$

where $Q$ is the proportional factor $\left(\mu \mathrm{F} \mathrm{s}{ }^{\mathrm{n}-1}\right), n$ is the CPE exponent associated to the phase shift, which can be used as a measure of surface irregularity, $j$ is an imaginary number, and $\omega$ is the angular frequency in $\mathrm{rad} \mathrm{s}^{-1}$.

The double layer capacitance or the pseudo capacitance $\left(\mathrm{C}_{\mathrm{di}}\right)$ values and the relaxation time constant $(\tau)$ of the charge transfer process were obtained using Equations (9) and (10), respectively.

$$
\begin{aligned}
& C_{d l}=\left(Q \times R_{t}^{1-n}\right)^{\frac{1}{n}} \\
& \tau=R_{t} \times C_{d l}
\end{aligned}
$$

The middle frequency region of $\log (f)-\log |Z|$ plots (Fig. 6b) should report slopes $(\varphi)$ that reflect the gap compared to an ideal capacitor. The chi-square $\left(\chi^{2}\right)$ was used in the EIS method to measure the quality of fitting to the proposed equivalent circuit, in order to evaluate the precision of the fitted data. It was calculated as follows [45]: 


$$
\chi^{\prime 2}=\sum_{i=1}^{n} \frac{\mid P_{\text {mea }}(i)-\left.P_{\text {model }}\left(f_{i}, \text { para }\right)\right|^{2}}{D_{i}^{2}}
$$

where $D_{i}$ is the standard deviation, $P_{\text {mea }}(i)$ is the measured impedance at the $f_{i}$ frequency, $P_{\text {model }}\left(f_{i}\right.$, para $)$ depends on the chosen model, and para is the model parameter ( $R t, R s$ and $Q$ ).

The low values of $\chi^{2}$ in Table 4 indicate that the fitted data were in good agreement with the experimental results. Thereafter, the inhibiting efficiency $\left(\eta_{E I S} \%\right)$ was evaluated using the following equation:

$$
\eta_{E I S} \%=\left(1-\frac{R_{t}}{R_{t / \text { inh }}}\right) \times 100
$$

where $R_{t}$ and $R_{t / \text { inh }}$ stand for the charge-transfer resistance of the mild steel in TSEO absence and presence, respectively.

Table 4. EIS data of mild steel in $1 \mathrm{M} \mathrm{HCl}$ containing different TSEO concentrations

\begin{tabular}{|c|c|c|c|c|c|c|c|c|c|}
\hline $\begin{array}{l}\mathrm{C}_{\text {inh }} \\
g L^{-1}\end{array}$ & $\begin{array}{c}R s \\
\Omega \mathrm{cm}^{2} \\
\end{array}$ & $\begin{array}{c}R t \\
\Omega \mathrm{cm}^{2}\end{array}$ & $\begin{array}{c}C_{d l} \\
\mu F \mathrm{~cm}^{-2}\end{array}$ & $\begin{array}{c}\tau \\
m s\end{array}$ & $\begin{array}{c}Q \\
\mu F s^{n-1}\end{array}$ & $n$ & $\varphi$ & $\chi^{2}$ & $\begin{array}{c}\text { ๆEIS } \\
\% \\
\end{array}$ \\
\hline Blank & $1.667 \pm 0.229$ & $55.99 \pm 0.45$ & 152.60 & 8.54 & $357.00 \pm 36.42$ & 0.8215 & -0.62 & 0.0930 & - \\
\hline 0.5 & $1.703 \pm 0.223$ & $130.40 \pm 0.46$ & 75.86 & 9.89 & $163.00 \pm 7.14$ & 0.8343 & -0.67 & 0.9974 & 57.06 \\
\hline 1 & $1.951 \pm 0.220$ & $168.40 \pm 0.45$ & 69.80 & 11.75 & $141.60 \pm 4.67$ & 0.8408 & -0.70 & 0.5213 & 66.75 \\
\hline 1.5 & $2.153 \pm 0.215$ & $217.40 \pm 0.44$ & 60.66 & 13.18 & $109.80 \pm 2.81$ & 0.8629 & -0.74 & 0.7070 & 74.24 \\
\hline 2 & $2.239 \pm 0.213$ & $240.70 \pm 0.44$ & 57.08 & 13.74 & $98.69 \pm 2.29$ & 0.8723 & -0.76 & 0.2114 & 76.73 \\
\hline
\end{tabular}
at $293 \mathrm{~K}$.

Table 4 presents the different electrochemical impedance parameters acquired from the experimental data fitting; the evaluation of the margins of error for certain parameters is also indicated. Indeed, by increasing TSEO concentrations, $R_{t}$ values tend to increase and reach a maximum value of $240.7 \Omega \mathrm{cm}^{2}$ at $2 \mathrm{~g} \mathrm{~L}^{-1}$ of TSEO. The increase in $R_{t}$ values demonstrates the protection effect of the inhibitor, due to the gradual replacement of water molecules and ions by the adsorption of TSEO components onto the mild steel surface, hence decreasing the degree of mild steel dissolution [46-47]. The value of the proportional factor $(Q)$ of $C P E$ conversely varies with TSEO concentration. Moreover, $\mathrm{C}_{\mathrm{dl}}$ values decrease with the increase in TSEO concentration. This result is a consequence of an increase in the surface coverage by the essential oil compounds, which confirms the increase in $\eta_{\text {EIS }} \%$.

On the other hand, in TSEO absence, the calculated value of the relaxation time constant $(\tau)$ is found to be $8.54 \mathrm{~ms}$. In its turn, TSEO addition to a $1 \mathrm{M} \mathrm{HCl}$ solution caused an increase in $\tau$ value at $1.5 \mathrm{~g} \mathrm{~L}^{-1}(\tau=13.18 \mathrm{~ms})$, which remained approximately unchanged, suggesting that charge and discharge rates to the metal/solution interface, considered as an electrical capacitor, were significantly decreased.

The adsorption of TSEO molecules onto the surface decreases its electrical capacity, because they displace the ions and the water molecules initially 
adsorbed onto the mild steel surface [48]. However, this decrease in electrical capacity may be attributed to the formation of a protective film on the mild steel surface. Hence, the thickness of the formed film $(\delta)$ is related to $\mathrm{C}_{\mathrm{dl}}$, according to Helmholtz model given by Equation (13) [49]:

$$
\delta=\frac{\varepsilon \times \varepsilon_{0}}{C_{d l}} \times S
$$

where $S$ is the surface area, $\delta$ is the protective film thickness, $\varepsilon_{0}$ is the medium relative dielectric constant, and $\varepsilon$ is the vacuum permittivity $\left(\varepsilon_{0}=8.8510^{-14} \mathrm{~F} \mathrm{~cm}^{-2}\right)$. However, when the inhibitor concentration increases, $C_{d l}$ decreases and, thus, the thickness $(\delta)$ of the protective film increases, which means that increasingly more TSEO compounds can be adsorbed onto the mild steel surface [50].

The $n$ parameter can be utilized as a gauge of the roughness or heterogeneity of the mild steel surface; it has a value ranged between 0-1. This result indicates a more homogenous surface. In Table 4, the value of a phase shift ranges from 0.8215 to 0.8723 , and does not significantly vary, which suggests that the charge transfer controlled the dissolution mechanism of mild steel in an aggressive solution, with and without TSEO [51]. On the other hand, Bode diagrams show that the slope $(\varphi)$ (Fig. 6b), ranges from -0.62 to -0.76 , which is related to the imperfect structure of the metal/solution interface [52].

\section{Comparison of the performance of some Thymus derivatives}

The use of essential oils as corrosion inhibitors has been widely reported by several authors $[5,12-13]$. Table 5 reports the percentage inhibition efficiency for some selected essential oils of Thymus derivatives, used as corrosion inhibitors for various materials in acidic media [18-23]. The values of corrosion inhibition efficiency, given in Table 5, derived from EIS measurements.

The comparison of the inhibitory efficiencies of Thymus derivatives [18-19] revealed that the major organic compounds of essential oils have the same skeleton, and only differ by the - $\mathrm{OH}$ substituent presence. Thus, the difference in the observed protective properties is predominately attributed to the electronic effect of the substituent type. Indeed, the inhibition efficiency was increasingly pronounced in the presence of a hydroxide functional group in p-Cymene molecule [19]. In addition, the presence of electron density in the phenyl ring with the hydroxide group led to an easier electron transfer from the functional groups to the metal surface, which provides greater adsorption, as reported by some researchers [53-54]. The obtained results reveal that, with an increasing donor property of the substituent, the inhibition efficiency of the inhibitor is increased.

On the other hand, inspection of Borneol chemical structure [20-21] reveals that the compound is easily hydrolysable, and that it can adsorb onto the metal surface via the lone pair of electrons present on oxygen atoms, making a barrier for charge and mass transfer, which leads to a decrease in the interaction of the metal with aggressive solutions. The formation of a layer essentially blocked $\mathrm{H}^{+}$ discharge and metal dissolution, so that the protection efficiency increased, even 
at low inhibitor concentrations $\left(1 \mathrm{~g} \mathrm{~L}^{-1}\right)$ [26,55]. However, the observed effect may not be due to the major constituents alone, as even the minor constituents may act to potentiate the inhibitive effects.

Table 5. Percentage of corrosion inhibition for some essential oils obtained from Thymus derivatives in acidic media on different matrices.

\begin{tabular}{|c|c|c|c|c|c|c|c|c|}
\hline $\begin{array}{c}\text { Essential } \\
\text { oil }\end{array}$ & Material & $\begin{array}{c}\text { Test } \\
\text { solution }\end{array}$ & $\begin{array}{c}\text { Optimum } \\
\text { concentration }\end{array}$ & $\begin{array}{l}\text { Inhibition } \\
\text { efficiency }\end{array}$ & $\begin{array}{c}\text { Geographic } \\
\text { location }\end{array}$ & $\begin{array}{c}\text { Major } \\
\text { composition }\end{array}$ & Structure & Reference \\
\hline $\begin{array}{l}\text { Thymus } \\
\text { capitatus }\end{array}$ & $\begin{array}{l}\text { Mild } \\
\text { steel }\end{array}$ & $\begin{array}{l}1 \mathrm{M} \\
\mathrm{HCl}\end{array}$ & $5 \mathrm{~mL} \mathrm{~L}^{-1}$ & $65.5 \%$ & $\begin{array}{l}\text { North-East } \\
\text { of Morocco }\end{array}$ & p- Cymene & & [18] \\
\hline $\begin{array}{l}\text { Thyme } \\
\text { vulgaris }\end{array}$ & $\begin{array}{l}\text { Mild } \\
\text { steel }\end{array}$ & $\begin{array}{l}1 \mathrm{M} \\
\mathrm{HCl}\end{array}$ & $2 \mathrm{~g} \mathrm{~L}^{-1}$ & $93 \%$ & $\begin{array}{l}\text { South of } \\
\text { Morocco }\end{array}$ & Thymol & & [19] \\
\hline $\begin{array}{l}\text { Thymus } \\
\text { algeriensis }\end{array}$ & $\begin{array}{l}\text { Mild } \\
\text { steel }\end{array}$ & $\begin{array}{l}1 \mathrm{M} \\
\mathrm{HCl}\end{array}$ & $1 \mathrm{~g} \mathrm{~L}^{-1}$ & $91 \%$ & $\begin{array}{l}\text { Eastern of } \\
\text { Morocco }\end{array}$ & Borneol & & [20] \\
\hline $\begin{array}{l}\text { Thymus } \\
\text { sahraouian }\end{array}$ & $\begin{array}{l}\text { Mild } \\
\text { steel }\end{array}$ & $\begin{array}{l}1 \mathrm{M} \\
\mathrm{HCl}\end{array}$ & $2 \mathrm{~g} \mathrm{~L}^{-1}$ & $76.73 \%$ & $\begin{array}{l}\text { South of } \\
\text { Morocco }\end{array}$ & Durenol & & - \\
\hline $\begin{array}{l}\text { Thymus } \\
\text { pallidus }\end{array}$ & $\begin{array}{l}\text { Carbon } \\
\text { steel }\end{array}$ & $\begin{array}{l}1 \mathrm{M} \\
\mathrm{HCl}\end{array}$ & $1 \mathrm{~g} \mathrm{~L}^{-1}$ & $88.75 \%$ & $\begin{array}{l}\text { South of } \\
\text { Morocco }\end{array}$ & Borneol & & [21] \\
\hline $\begin{array}{l}\text { Thymus } \\
\text { satureioides }\end{array}$ & Tinplate & $\begin{array}{c}0.5 \mathrm{M} \\
\mathrm{HCl}\end{array}$ & $6 \mathrm{~g} \mathrm{~L}^{-1}$ & $87 \%$ & $\begin{array}{l}\text { South of } \\
\text { Morocco }\end{array}$ & Borneol & & [22] \\
\hline $\begin{array}{l}\text { Thymus } \\
\text { satureioides }\end{array}$ & $\begin{array}{l}\text { Carbon } \\
\text { steel }\end{array}$ & $\begin{array}{c}0.5 \mathrm{M} \\
\mathrm{H}_{2} \mathrm{SO}_{4}\end{array}$ & $2 \mathrm{~g} \mathrm{~L}^{-1}$ & $95.97 \%$ & $\begin{array}{l}\text { South of } \\
\text { Morocco }\end{array}$ & Borneol & & [23] \\
\hline
\end{tabular}

From Table 5, it is clear that the major compound of Thymus derivatives essential oils [18-20] is variable according to the harvest area and the development stage [26]. Thus, it is logical to assume that the adsorption mechanism is mainly responsible for the good protective properties of essential oils for various metals in different acidic media [18-23]. It can be easily concluded that corrosion inhibition occurs by a synergistic effect of the different active molecules present in each essential oil.

By comparing these results, we can see that TSEO is an effective inhibitor in $1 \mathrm{M}$ $\mathrm{HCl}$. The best value of inhibition efficiency was obtained even at lower concentrations $\left(76.73 \%\right.$ at $\left.2 \mathrm{~g} \mathrm{~L}^{-1}\right)$.

\section{Comparison of the overall results issued from different methods}

Fig. 8 shows the histogram of the comparative study of the inhibition efficiency $(\eta \%)$ data for all investigated concentrations of TSEO extracted from the different undertaken weight loss, potentiodynamic polarization (Tafel, Stern- 
Geary, and Stern) and EIS methods. It is noted from the histogram that $\eta \%$ increased with higher concentrations of essential oil in the same manner from all the five methods. A good correlation was observed between the weight loss measurements and potentiodynamic polarization, along with electrochemical impedance spectroscopy studies. The best $\eta \%$ was achieved at $2 \mathrm{~g} \mathrm{~L}^{-1}$ of TSEO.

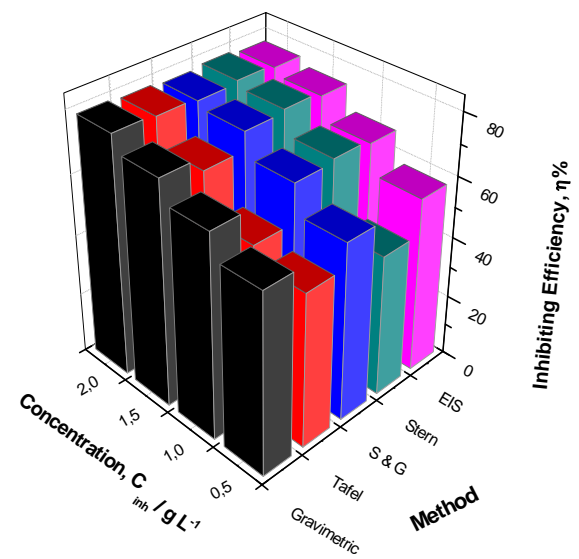

Figure 8. Comparison of the inhibition efficiency $(\eta \%)$ values obtained by weight loss, Tafel, Stern, Stern-Geary and EIS methods.

\section{Effect of temperature}

In order to have more information about TSEO performance and the nature of adsorption and activation processes, the effect of temperature was studied using gravimetric experiments in uninhibited and inhibited media, after $2 \mathrm{~h}$ of immersion in the temperature range of 293-333 K.

Fig. 9 shows that the corrosion rate $\left(\mathrm{W}_{\text {corr }}\right)$ increases with a rise in temperature, and it is more pronounced for the blank solution. It is obvious that the weightloss was approximately 13 and 17 times superior, at $333 \mathrm{~K}$, when compared to $293 \mathrm{~K}$, in the absence and presence of $2 \mathrm{~g} \mathrm{~L}^{-1}$ of TSEO, respectively. Besides, the inhibition efficiency $\left(\eta_{\mathrm{WL}} \%\right)$ decreased with a rise in temperature from 293 to $333 \mathrm{~K}$, indicating the increased rate of the dissolution process and the partial desorption of TSEO from the mild steel surface, as reported elsewhere [56]. This fact clearly means a decrease in the strength of the adsorption process at higher temperatures. Meanwhile, we can propose a physisorption mode of TSEO onto the mild steel surface.

The dependence of $\mathrm{W}_{\text {corr }}$ on temperature can be expressed by the Arrhenius Equation (14). An alternative formulation of Arrhenius is called transition state, given by Equation (15).

$$
\begin{aligned}
\ln W_{\text {corr }} & =\ln F-\frac{E_{a}}{R \times T} \\
\ln \frac{W_{\text {corr }}}{T} & =\left(\ln \left(\frac{R}{N \times h}\right)+\frac{\Delta S^{*}}{R}\right)-\frac{\Delta H^{*}}{R T}
\end{aligned}
$$

In Equation (14), $E_{a}$ is the apparent effective activation energy, $R$ is the general gas constant, $T$ is the absolute temperature, and $F$ is the frequency factor. 
In Equation (15), $N$ is the Avogadro's number, $h$ is the Planck's constant, $\Delta S^{*}$ is the entropy of activation and $\Delta H^{*}$ is the enthalpy of activation.

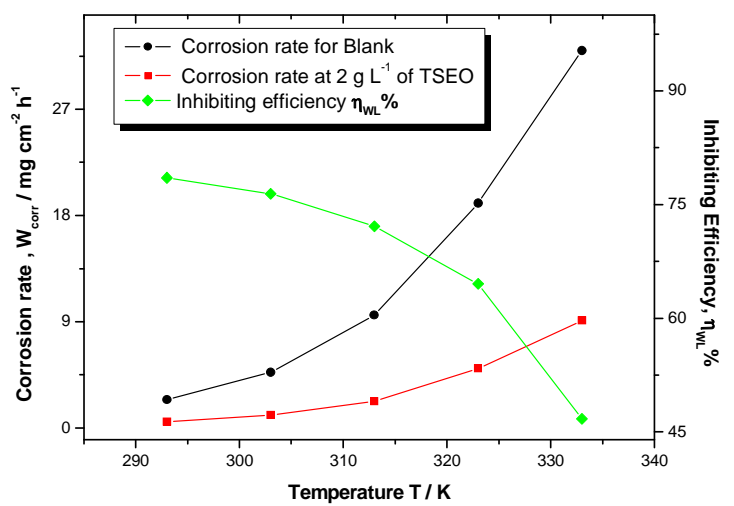

Figure 9. Evolution of the corrosion rate and inhibition efficiency for mild steel in $1 \mathrm{M}$ $\mathrm{HCl}$, with and without $2 \mathrm{~g} \mathrm{~L}^{-1}$ of TSEO at different temperatures.

Fig. 10 shows the variations of the logarithm of $\mathrm{W}_{\text {corr, }}$ in TSEO presence and absence, against the reciprocal temperature. All of the kinetic parameters extracted from Fig. 10 are given in Table 6.

It is obvious that the linear regression coefficients $\left(\mathrm{R}^{2}\right)$ are close to unity, indicating that mild steel corrosion in $1 \mathrm{M} \mathrm{HCl}$ can be elucidated using the kinetic model. In literature, the decrease of the inhibition efficiency ( $\left.\eta_{w L} \%\right)$ with a rise in temperature (which refers to a superior value of apparent activation corrosion energy ( $\left.E_{a}\right)$, when compared to the blank), is interpreted as a physisorption phenomenon. In its turn, the inferior value of the apparent activation corrosion energy in an inhibited solution, in comparison with the blank solution, is often interpreted as an indication of a chemisorption phenomenon [57].

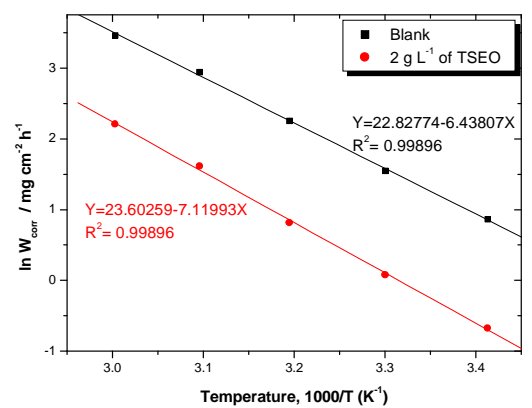

(a)

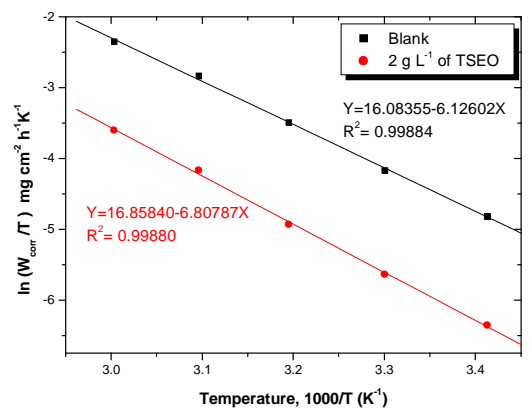

(b)

Figure 10. Arrhenius equation: (a) linearized form and (b) transition state of mild steel in $1 \mathrm{M} \mathrm{HCl}$, with and without $2 \mathrm{~g} \mathrm{~L}^{-1}$ of TSEO.

Furthermore, $E_{a}$ given in Table 6 is found to be 53.52 and $59.19 \mathrm{~kJ} \mathrm{~mol}^{-1}$ for the corrosion process, in TSEO absence and presence, respectively. In addition, the frequency factor (F) increased by more than twice, while $\eta_{\mathrm{WL}} \%$ decreased. However, the rise in temperature, which goes together with a slow increase in $E_{a}$ 
by $6 \mathrm{~kJ} \mathrm{~mol}^{-1}$, can be interpreted as an indication of a columbic or physical type of adsorption [58].

Table 6. The values of activation parameters $F, E_{a}, \Delta H^{*}$ and $\Delta S^{*}$ for mild steel in $1 \mathrm{M}$ $\mathrm{HCl}$, in the absence and presence of $2 \mathrm{~g} \mathrm{~L}^{-1}$ of TSEO.

\begin{tabular}{lll}
\hline Kinetic parameters & Blank & TSEO \\
\hline$F / \mathrm{mg} \mathrm{cm}^{-2} \mathrm{~h}^{-1}$ & $8.20210^{9}$ & $17.8010^{9}$ \\
$E_{a} / \mathrm{kJ} \mathrm{mol}^{-1}$ & 53.52 & 59.19 \\
$\Delta H^{*} / \mathrm{kJ} \mathrm{mol}^{-1}$ & 50.93 & 56.60 \\
$\Delta S^{*} / \mathrm{J} \mathrm{K}^{-1} \mathrm{~mol}^{-1}$ & -63.82 & -57.37 \\
$E_{a}-\Delta H^{*} / \mathrm{kJ} \mathrm{mol}^{-1}$ & 2.59 & 2.59 \\
\hline
\end{tabular}

The positive sign of the activated enthalpy $\left(\Delta H^{*}\right)$ means that the dissolution phenomenon is of endothermic nature, and the higher value, in TSEO presence, reveals that the metal dissolution becomes slow [27-59]. The higher values of the entropy of activation $\left(\Delta S^{*}\right)$ in an inhibited solution can be interpreted as an increase in disorder, as the reactants are converted to the activated complexes [660]. We note that the activated enthalpy $\left(\Delta H^{*}\right)$ value and the apparent effective activation energy $\left(E_{a}\right)$ value vary in similar way, allowing to verify the corresponding thermodynamic equation [6]:

$$
\Delta H^{*}=E_{a}-(R \times T)
$$

\section{Adsorption isotherm}

The adsorption isotherm can be used to determine if the TSEO effect is mainly due to the adsorption onto the mild steel surface; i.e., to its blocking. Hence, the type of adsorption isotherm can offer additional information concerning the properties of the studied inhibitor. The adsorption process of TSEO components is a permutation reaction where the adsorbed water molecules are being displaced from the mild steel surface, and replaced by TSEO molecules, according to the following equation [49]:

$$
\mathrm{Org}_{(s o l)}+n \mathrm{H}_{2} \mathrm{O}_{(a d s)} \leftrightarrow \mathrm{Org}_{(a d s)}+n \mathrm{H}_{2} \mathrm{O}_{(\text {sol })}
$$

where $\operatorname{Org}_{(s o l)}$ is the organic molecule in a aggressive solution, $\operatorname{Org}_{(a d s)}$ is the adsorbed organic molecule onto the electrode surface, $\mathrm{H}_{2} \mathrm{O}_{(\text {ads })}$ is the water molecule onto the electrode surface, and $n$ is the coefficient that represents water molecules replaced by a TSEO molecule unit.

It is well established that the inhibition efficiency $(\eta \%)$ depends on the number and type of active sites at the mild steel interface, the molecular size of the inhibitor, the charge density, the metallic complex formation, and the mild steelinhibitor interaction [61]. The fractional surface coverage $(\theta)$ values are calculated from weight-loss, EIS measurements and potentiodynamic polarization methods (Tafel, Stern-Geary, and Stern) at different TSEO concentrations and at $293 \mathrm{~K}$, using the following equation [62]:

$$
\theta=\frac{\eta \%}{100}
$$


The most frequently used isotherms are Langmuir, Temkin, and Frumkin [63]. It has been shown that the best suitable isotherm for TSEO adsorption onto the mild steel surface in a $1 \mathrm{M} \mathrm{HCl}$ solution is the Langmuir model.

The straight lines were traced using the least squares method. The experimental data (points) and fitting data (lines) for the isotherm model are plotted in Fig. 11.

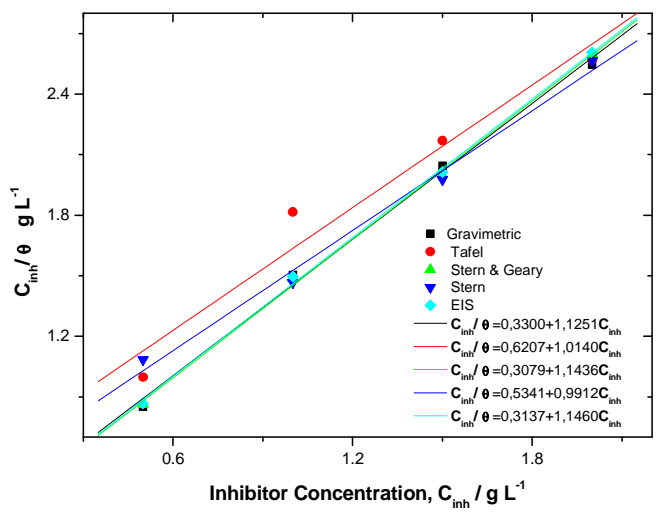

Figure 11. Plots of the Langmuir adsorption isotherm model of TSEO onto the mild steel surface at $293 \mathrm{~K}$, obtained at the five undertaken methods.

The results of linear regression are given in Table 7 . It is noticeable that the obtained fit quality refers to $\mathrm{R}^{2}$, which reached 0.99 . The data fitting lines have slopes very close to unit, which suggests that the experimental data are well explained by the Langmuir adsorption isotherm [6]. Consequently, it is concluded that a single-layer inhibitor film forms on the electrode surface, and that there are no interactions between the adsorbed species onto the electrode surface [64-66].

Table 7. Parameter values issued from the Langmuir adsorption isotherm model for TSEO adsorption onto the mild steel surface in $1 \mathrm{M} \mathrm{HCl}$ at $293 \mathrm{~K}$.

\begin{tabular}{lll}
\hline Method & $R^{2}$ & Slope \\
\hline Weight-loss & 0.9962 & 1.1251 \\
Tafel & 0.9577 & 1.0140 \\
S\&G & 0.9986 & 1.1436 \\
Stern & 0.9911 & 0.9912 \\
EIS & 0.9988 & 1.1460 \\
\hline
\end{tabular}

\section{SEM and EDX results}

The high-resolution SEM micrographs $(50 \mu \mathrm{m})$ of mild steel strips are recorded, in order to examine the changes occurred during the corrosion process, before and after immersion in $1 \mathrm{M} \mathrm{HCl}$, without and with TSEO (Figs. $12 \mathrm{a}-\mathrm{c})$.

A parallel description of the polished mild steel surface before immersion in the corrosive solution is linked to the abrading scratches (Fig. 12a). Figs. 12 b-c show the mild steel surface after $24 \mathrm{~h}$ of immersion in $1 \mathrm{M} \mathrm{HCl}$, with and without TSEO. The SEM micrograph (Fig. 12b) shows that the mild steel surface was strongly damaged in TSEO absence, due to an excessive mild steel dissolution in 
the corrosive solution, and to the increased number and/or depth of pits. On the other hand, in TSEO presence (Fig. 12c), the mild steel surface was remarkably improved, and fewer corrosion attacks, except polishing lines, were observed in comparison to the mild steel surface in TSEO absence, indicating a considerable reduction in the corrosion rate. This improvement in surface morphology was probably due to the formation of a protective film of TSEO components onto the mild steel surface, which was responsible for the corrosion inhibition [7].
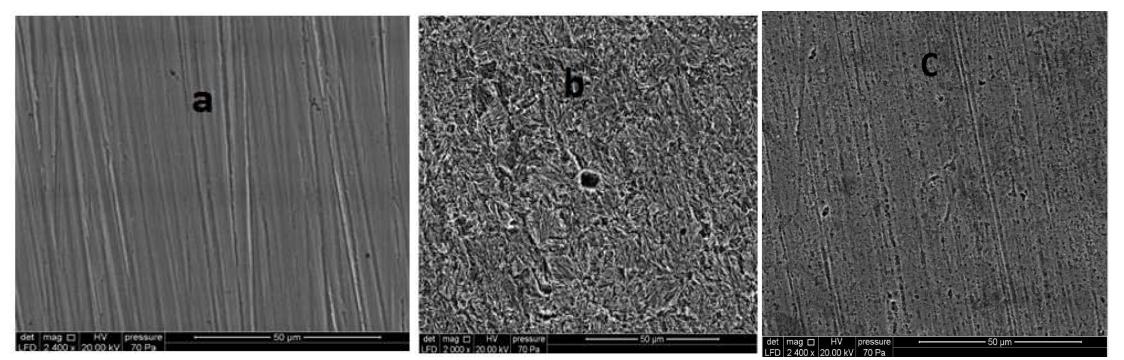

Figure 12. SEM micrographs of the mild steel surface: (a) mild steel surface after being polished, (b) mild steel surface after $24 \mathrm{~h}$ immersion in $1 \mathrm{M} \mathrm{HCl}$, and (c) mild steel surface after $24 \mathrm{~h}$ immersion in $1 \mathrm{M} \mathrm{HCl}$ with $2 \mathrm{~g} \mathrm{~L}^{-1}$ of TSEO.
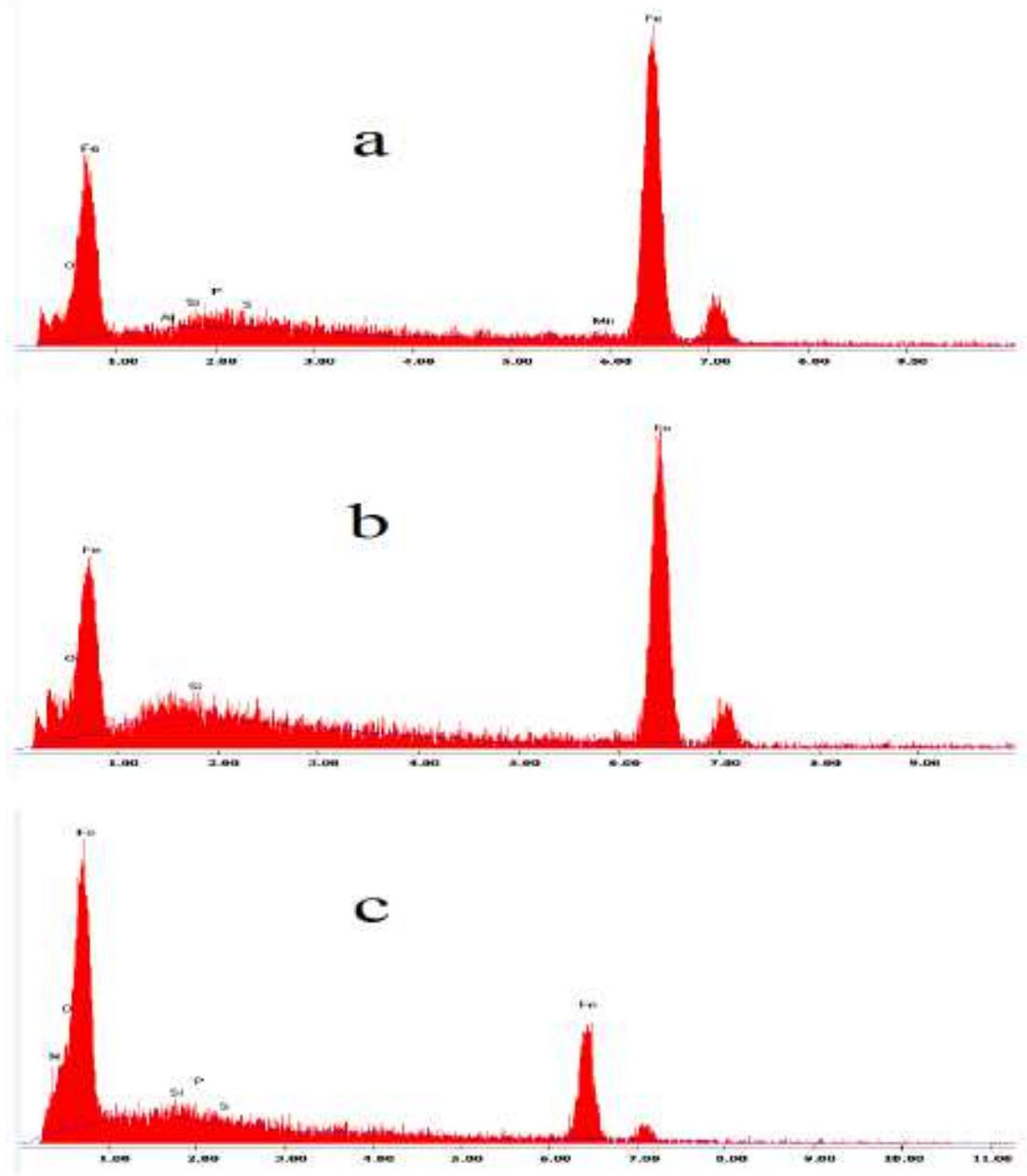

Figure 13. EDX spectra of mild steel surface: (a) before immersion in $1 \mathrm{M} \mathrm{HCl}$, (b) after $24 \mathrm{~h}$ of immersion in $1 \mathrm{M} \mathrm{HCl}$, and (c) after $24 \mathrm{~h}$ of immersion in $1 \mathrm{M} \mathrm{HCl}+$ $2 \mathrm{~g} \mathrm{~L}^{-1}$ of TSEO. 
Table 8. Percentage of atomic contents of elements obtained from EDX spectra.

\begin{tabular}{ccccc}
\hline Mild steel sample & \multicolumn{4}{c}{ Element $(\%$ at $)$} \\
\cline { 2 - 5 } & $\mathbf{O}$ & $\mathbf{N}$ & $\mathbf{S}$ & $\mathbf{P}$ \\
\hline Polished & 1.98 & - & 0.02 & 0.01 \\
$1 \mathrm{M} \mathrm{HCl}$ & 2.56 & - & - & - \\
$2 \mathrm{~g} \mathrm{~L}^{-1}$ of TSEO & 10.78 & 15.12 & 0.98 & 1.30 \\
\hline
\end{tabular}

Thereafter, an EDX qualitative analysis (Fig. 13) and quantitative spectra (Table 8) are given to determine the principal potential sites present in the different TSEO components, and responsible for the adsorption process.

Fig. 13 presents an EDX panorama recorded for a mild steel specimen exposed for $24 \mathrm{~h}$ in $1 \mathrm{M} \mathrm{HCl}$, in the absence and presence of $2 \mathrm{~g} \mathrm{~L}^{-1}$ of TSEO.

In the blank solution, EDX spectrum (Fig. 13a) shows the characteristic peaks of some of the elements constituting the mild steel specimen. In TSEO presence (Fig. 13c), EDX spectrum shows an additional line characteristic of the existence of $\mathrm{N}$ [65]. In addition, $\mathrm{O}, \mathrm{S}$, and $\mathrm{P}$ signals are significantly enhanced upon adding TSEO into $1 \mathrm{M} \mathrm{HCl}$. This indicates that TSEO molecules, as major components of the essential oil (Fig. 2), are adsorbed onto the mild steel surface. These results confirm those derived from weight loss, potentiodynamic polarization and EIS measurements, suggesting that a surface film inhibits the mild steel dissolution, and hence retards both cathodic and anodic reactions.

\section{Conclusions}

According to the experimental results, the following conclusions can be drawn:

1. The potentiodynamic polarization curves indicate that TSEO acts as mixed type inhibitor with a predominant anodic action.

2. EIS study reveals that TSEO reduced the corrosion rate by increasing the charge transfer resistance of the system, and that the equivalent circuit fitted well with a constant phase element.

3. The confrontation of gravimetric, potentiodynamic polarization (Tafel, Stern, Stern-Geary methods), and EIS measurements showed good agreement among them.

4. The increase in the frequency factor, as well as the apparent activation energy $\left(E_{a}\right)$ value, along with a decrease in the inhibition efficiency suggest that TSEO underwent physical adsorption onto the mild steel surface.

5. The adsorption of TSEO molecules obeyed Langmuir adsorption isotherm model.

6. SEM examination and EDX analysis of the mild steel surface, in TSEO presence, confirmed the existence of a protective adsorbed film.

\section{References}

1. Revie RW, Uhlig HH. Corrosion and Corrosion Control: An introduction to corrosion science and engineering. 2008. 
2. Roberge P. Corrosion engineering: principles and practice. 2008.

3. Zhang QB, Hua YX. Corrosion inhibition of mild steel by alkylimidazolium ionic liquids in hydrochloric acid. Electrochim Acta. 2009;54:1881-1887.

4. Halambek J, Berković K, Vorkapić-Furač J. The influence of Lavandula angustifolia L. oil on corrosion of Al-3Mg alloy. Corros Sci. 2010;52:39783983.

5. Boumhara K, Tabyaoui M, Jama C, et al. Artemisia Mesatlantica essential oil as green inhibitor for carbon steel corrosion in $1 \mathrm{M} \mathrm{HCl}$ solution: Electrochemical and XPS investigations. J Ind Eng Chem. 2015;29:146-155.

6. Zarrok H, Zarrouk A, Hammouti B. Corrosion control of carbon steel in phosphoric acid by purpald - Weight loss, electrochemical and XPS studies. Corros Sci. 2012;64:243-252.

7. Solmaz R. Investigation of corrosion inhibition mechanism and stability of Vitamin B1 on mild steel in 0.5M HCl solution. Corros Sci. 2014;81:75-84.

8. Amin MA, Abd El-Rehim SS, El-Sherbini EEF, et al. The inhibition of low carbon steel corrosion in hydrochloric acid solutions by succinic acid. Part I. Weight loss, polarization, EIS, PZC, EDX and SEM studies. Electrochim Acta. 2007;52:3588-3600.

9. Kesavan D, Gopiraman M, Sulochana N. Green Inhibitors for Corrosion of Metals : A Review. Chem Sci Rev Lett. 2012;1:1-8.

10. Faska Z, Majidi L, Fihi R, et al. Synthesis and anticorrosive effect of epoxyallylmenthols on steel in molar hydrochloric acid. Pigm Resin Technol. 2007;36:293.

11. Benabdellah M, Benkaddour M, Hammouti B, et al. Inhibition of steel corrosion in 2 M H3PO4 by artemisia oil. Appl Surf Sci. 2006;252:62126217.

12. N. National Association of Corrosion Engineers., T. NACE International., M. NATESAN, S.C. MURUGAVEL, Materials performance., National Association of Corrosion 1974. http://cat.inist.fr/?aModele $=$ afficheN\&cpsidt=21902502 (accessed June 20, 2017).

13. Zerga B, Sfaira M, Rais Z, et al. Lavender oil as an ecofrindly inhibitor for mild steel in $1 \mathrm{M} \mathrm{HCl}$. Matériaux Tech. 2009;97:297-305.

14. Raja PB, Qureshi AK, Abdul Rahim A, et al. Neolamarckia cadamba alkaloids as eco-friendly corrosion inhibitors for mild steel in $1 \mathrm{M} \mathrm{HCl}$ media. Corros Sci. 2013;69:292-301.

15. Bentrah H, Rahali Y, Chala A. Gum Arabic as an eco-friendly inhibitor for API 5L X42 pipeline steel in HCl medium. Corros Sci. 2014;82:426-431.

16. Mourya P, Banerjee S, Singh MM. Corrosion inhibition of mild steel in acidic solution by Tagetes erecta (Marigold flower) extract as a green inhibitor. Corros Sci. 2014;85:352-363.

17. Okafor PC, Ikpi ME, Uwah IE, et al. Inhibitory action of Phyllanthus amarus extracts on the corrosion of mild steel in acidic media. Corros Sci. 2008;50:2310-2317.

18. El Ouadi JCY, Lahhit N, Bouyanzer A, et al. The use of essential oil of thymus capitatus originating from north-east morocco, as eco-friendly 
corrosion inhibitors of mild steel in hydrochloric acid solution. Int J Dev Res. 2016;6:6867-6874.

19. El Hajjaji F, Greche H, Taleb M, et al. Application of essential oil of thyme vulgaris as green corrosion inhibitor for mild steel in1MHCl. J Mater Environ Sci. 2016;7:567-578.

20. Hamdani I, El Ouariachi E, Mokhtari O, et al. Chemical constituents and corrosion inhibition of mild steel by the essential oil of Thymus algeriensis in 1.0 M hydrochloric acid solution. Der Pharma Chem. 2017;8:252-264.

21. Elbouchtaoui MC, Anejjar A, Salghi R, et al. Inhibition of steel corrosion in $1 \mathrm{M} \mathrm{HCl}$ by the essential oil of Thymus pallidus. Der Pharma Chem. 2014;6:406-414.

22. Bammou L, Chebli B, Salghi R, et al. Thermodynamic properties of Thymus satureioides essential oils as corrosion inhibitor of tinplate in $0.5 \mathrm{M} \mathrm{HCl}$ : chemical characterization and electrochemical study. Green Chem Lett Rev. 2010;3:173-178.

23. Taoufik F, Anejjar A, Asdadi A, et al. Synergic effect between Argania spinosa cosmetic oil and Thymus satureioides essential oil for the protection of the carbon steel against the corrosion in sulfuric acid medium. J Mater Environ Sci. 2017;8:582-593.

24. Houbairi S, Essahli M, Lamiri A. Inhibition of Copper Corrosion in $2 \mathrm{M}$ HNO3 by the Essential Oil of Thyme Morocco. Port Electrochim Acta. 2013;31:221-233.

25. Parthipan P, Narenkumar J, Elumalai P, et al. Neem extract as a green inhibitor for microbiologically influenced corrosion of carbon steel API 5LX in a hypersaline environments. J Mol Liq. 2017;240:121-127.

26. Rani BEA, Basu BBJ. Green inhibitors for corrosion protection of metals and alloys: An overview. Int J Corros. 2012;2012.

27. Hussin MH, Abdul A, Nasir M, et al. The capability of ultrafiltrated alkaline and organosolv oil palm ( Elaeis guineensis ) fronds lignin as green corrosion inhibitor for mild steel in $0.5 \mathrm{M} \mathrm{HCl}$ solution. Measurement. 2016;78:90103.

28. Musa AY, Kadhum AAH, Mohamad AB, et al. Experimental and theoretical study on the inhibition performance of triazole compounds for mild steel corrosion. Corros Sci. 2010;52:3331-3340.

29. Li L, Zhang X, Lei J, et al. Adsorption and corrosion inhibition of Osmanthus fragran leaves extract on carbon steel. Corros Sci. 2012;63:8290.

30. Qian B, Wang J, Zheng M, et al. Synergistic effect of polyaspartic acid and iodide ion on corrosion inhibition of mild steel in H2SO4. Corros Sci. 2013;75:184-192.

31. Bentiss F, Traisnel M, Vezin H, et al. 2,5-Bis(4-dimethylaminophenyl)1,3,4-oxadiazole and 2,5-bis(4-dimethylaminophenyl)-1,3,4-thiadiazole as corrosion inhibitors for mild steel in acidic media. Corros Sci. 2004;46:2781-2792.

32. Poorqasemi E, Abootalebi O, Peikari M, et al. Investigating accuracy of the Tafel extrapolation method in $\mathrm{HCl}$ solutions. Corros Sci. 2009;51:1043- 
1054.

33. Verma C, Quraishi MA, Ebenso EE, et al. 3-Amino alkylated indoles as corrosion inhibitors for mild steel in $1 \mathrm{M} \mathrm{HCl}$ : Experimental and theoretical studies. J Mol Liq. 2016;219:647-660.

34. Anupama KK, Ramya K, Joseph A. Electrochemical and computational aspects of surface interaction and corrosion inhibition of mild steel in hydrochloric acid by Phyllanthus amarus leaf extract (PAE). J Mol Liq. 2016;216:146-155.

35. Rameshkumar S, Danaee I, RashvandAvei M, et al. Quantum chemical and experimental investigations on equipotent effects of (+)R and (-)S enantiomers of racemic amisulpride as eco-friendly corrosion inhibitors for mild steel in acidic solution. J Mol Liq. 2015;212:168-186.

36. Solmaz R, Kardaş G, Çulha $M$, et al. Investigation of adsorption and inhibitive effect of 2-mercaptothiazoline on corrosion of mild steel in hydrochloric acid media Electrochim Acta. 2008;53:5941-5952.

37. Stern M, Geary AL. Electrochemical Polarization. J Electrochem Soc. 1957; 104:559.

38. Perez N. Electrochemistry and Corrosion Science. Igarss. 2014; 2014. p 1-5.

39. Rochdi A, Kassou O, Dkhireche N, et al. Inhibitive properties of 2,5-bis(nmethylphenyl)-1,3,4-oxadiazole and biocide on corrosion, biocorrosion and scaling controls of brass in simulated cooling water. Corros Sci. 2014;80:442-452.

40. Aljourani J, Raeissi K, Golozar MA. Benzimidazole and its derivatives as corrosion inhibitors for mild steel in $1 \mathrm{M} \mathrm{HCl}$ solution. Corros Sci. 2009;51:1836-1843.

41. Behpour M, Ghoreishi SM, Soltani N, et al. The inhibitive effect of some bis-N,S-bidentate Schiff bases on corrosion behaviour of 304 stainless steel in hydrochloric acid solution. Corros Sci. 2009;51:1073-1082.

42. Juttner K. Electrochemical impedance spectroscopy (EIS) of corrosion processes on inhomogeneous surfaces. Electrochim Acta. 1990;35:15011508.

43. Zarrouk A, Hammouti B, Lakhlifi T, et al. New 1H-pyrrole-2,5-dione derivatives as efficient organic inhibitors of carbon steel corrosion in hydrochloric acid medium: Electrochemical, XPS and DFT studies. Corros Sci. 2015;90:572-584.

44. Chaitra TK, Mohana KNS, Tandon HC. Thermodynamic, electrochemical and quantum chemical evaluation of some triazole Schiff bases as mild steel corrosion inhibitors in acid media. J Mol Liq. 2015;211:1026-1038.

45. Darowiki K. Corrosion Rate Measurements By Non-Linear Impedance. Corros Sci. 1998;40:495-508.

46. Quraishi MA, Singh A, Kumar V, et al. Green approach to corrosion inhibition of mild steel in hydrochloric acid and sulphuric acid solutions by the extract of Murraya koenigii leaves. Mater Chem Phys. 2010;122:114122.

47. Lebrini M, Bentiss F, Chihib NE, et al. Polyphosphate derivatives of guanidine and urea copolymer: Inhibiting corrosion effect of Armco iron in 
acid solution and antibacterial activity. Corros Sci. 2008;50:2914-2918.

48. Tourabi M, Nohair K, Traisnel M, et al. Electrochemical and XPS studies of the corrosion inhibition of carbon steel in hydrochloric acid pickling solutions by 3,5-bis(2-thienylmethyl)-4-amino-1,2,4-triazole. Corros Sci. 2013;75:123-133.

49. Verma C, Singh A, Pallikonda G, et al. Aryl sulfonamidomethylphosphonates as new class of green corrosion inhibitors for mild steel in $1 \mathrm{M} \mathrm{HCl}$ : Electrochemical, surface and quantum chemical investigation. J Mol Liq. 2015;209:306-319.

50. Bataillon SBS, Brunet C. Electrochemical Impedance Spectroscopy on Oxide Films Formed on Zircaloy 4 in High Temperature. Electrochim Acta. 1994;39:455-465.

51. Growcock F, Jasinski R. Time-resolved impedance spectroscopy of mild steel in concentrated hydrochoric acid. $\mathrm{J}$ Elechtrochemical Soc. 1989; $136: 2310$.

52. Solmaz R. Investigation of adsorption and corrosion inhibition of mild steel in hydrochloric acid solution by 5-(4-Dimethylaminobenzylidene) rhodanine. Corros Sci. 2014;79:169-176.

53. Hegazy MA, Ahmed HM, El-Tabei AS. Investigation of the inhibitive effect of p-substituted 4-(N,N,N-dimethyldodecylammonium bromide)benzylidenebenzene-2-yl-amine on corrosion of carbon steel pipelines in acidic medium. Corros Sci. 2011;53:671-678.

54. Noor EA, Al-Moubaraki AH. Thermodynamic study of metal corrosion and inhibitor adsorption processes in mild steel/1-methyl-4[4'(-X)-styryl pyridinium iodides/hydrochloric acid systems. Mater Chem Phys. 2008;110:145-154.

55. Shyamala M, Kasthuri PK. A comparative study of the inhibitory effect of the extracts of ocimum sanctum, aegle marmelos, and solanum trilobatum on the corrosion of mild steel in hydrochloric acid medium. Int $\mathrm{J}$ Corros. 2011;2011.

56. Schorr M, Yahalom J. The significance of the energy of activation for the dissolution reaction of metal in acids. Corros Sci. 1972;12:867-868.

57 Popova A. Temperature effect on mild steel corrosion in acid media in presence of azoles. Corros Sci. 2007;49:2144-2158.

58. Popova A, Sokolova E, Raicheva S, et al. AC and DC study of the temperature effect on mild steel corrosion in acid media in the presence of benzimidazole derivatives. Corros Sci. 2003;45:33-58.

59. Singh P, Srivastava V, Quraishi MA. Novel quinoline derivatives as green corrosion inhibitors for mild steel in acidic medium: Electrochemical, SEM, AFM, and XPS studies. J Mol Liq. 2016;216:164-173.

60. Banerjee S, Srivastava V, Singh MM. Chemically modified natural polysaccharide as green corrosion inhibitor for mild steel in acidic medium. Corros Sci. 2012;59:35-41.

61. Avci G. Corrosion inhibition of indole-3-acetic acid on mild steel in $0.5 \mathrm{M}$ HCl. Colloids Surf A Physicochem Eng Asp. 2008;317:730-736.

62. Singh P, Makowska-Janusik M, Slovensky P, et al. Nicotinonitriles as green 
corrosion inhibitors for mild steel in hydrochloric acid: Electrochemical, computational and surface morphological studies. J Mol Liq. 2016;220:7181.

63. Haque J, Srivastava V, Verma C, et al. Experimental and quantum chemical analysis of 2-amino-3-((4-((S)-2-amino-2-carboxyethyl)-1H-imidazol-2yl)thio) propionic acid as new and green corrosion inhibitor for mild steel in 1M hydrochloric acid solution. J Mol Liq. 2017;225:848-855.

64. El Hamdani N, Fdil R, Tourabi M, et al. Alkaloids extract of Retama monosperma (L.) Boiss. seeds used as novel eco-friendly inhibitor for carbon steel corrosion in $1 \mathrm{M} \mathrm{HCl}$ solution: Electrochemical and surface studies. Appl Surf Sci. 2015;375:1294-1305.

65. Gupta NK, Verma C, Quraishi MA, et al. Schiff's bases derived from 1-lysine and aromatic aldehydes as green corrosion inhibitors for mild steel: Experimental and theoretical studies. J Mol Liq. 2016;215:47-57. 